\title{
Perfectionism related to self-reported insomnia severity, but not when controlled for stress and emotion regulation
}

This article was published in the following Dove Press journal:

Neuropsychiatric Disease and Treatment

3 February 2015

Number of times this article has been viewed

\author{
Serge Brand ${ }^{1,2}$ \\ Roumen Kirov ${ }^{3}$ \\ Nadeem Kalak' \\ Markus Gerber ${ }^{2}$ \\ Uwe Pühse ${ }^{2}$ \\ Sakari Lemola ${ }^{4}$ \\ Christoph U Correll ${ }^{5}$ \\ Samuele Cortese ${ }^{6-8}$ \\ Till Meyer ${ }^{\prime}$ \\ Edith Holsboer-Trachsler' \\ 'Psychiatric Clinics of the University \\ of Basel, Center for Affective, Stress \\ and Sleep Disorders (ZASS), Basel, \\ Switzerland; ${ }^{2}$ Department of Sport, \\ Exercise and Health, Division \\ of Sport Science, University of \\ Basel, Basel, Switzerland; Institute \\ of Neurobiology, Bulgarian \\ Academy of Sciences, Sofia, Bulgaria; \\ ${ }^{4}$ Faculty of Psychology, University \\ of Basel, Basel, Switzerland; \\ ${ }^{5}$ Division of Psychiatric Research, \\ North Shore - Long Island Jewish \\ Health System, Zucker Hillside \\ Hospital, NY, USA; 'School of \\ Medicine, University of Nottingham, \\ Nottingham, UK; ${ }^{7}$ Centre for ADHD \\ and Neuro-developmental Disorders \\ Across Lifespan, Institute of Mental \\ Health, University of Nottingham, \\ Nottingham, UK; ${ }^{8} \mathrm{New}$ York \\ University Child Study Centre, \\ New York, NY, USA
}

Correspondence: Serge Brand Psychiatric Clinics of the University of Basel, Center for Affective, Stress and Sleep Disorders, Basel, Switzerland,

Wilhelm Klein-Strasse 27, 40I2 Basel, Switzerland

Tel +4I 613255 II4

Fax +4I 6I 3255513

Email serge.brand@upkbs.ch
Background: Perfectionism is understood as a set of personality traits such as unrealistically high and rigid standards for performance, fear of failure, and excessive self-criticism. Previous studies showed a direct association between increased perfectionism and poor sleep, though without taking into account possible mediating factors. Here, we tested the hypothesis that perfectionism was directly associated with poor sleep, and that this association collapsed, if mediating factors such as stress and poor emotion regulation were taken into account.

Methods: Three hundred and forty six young adult students ( $M=23.87$ years) completed questionnaires relating to perfectionism traits, sleep, and psychological functioning such as stress perception, coping with stress, emotion regulation, and mental toughness.

Results: Perfectionism was directly associated with poor sleep and poor psychological functioning. When stress, poor coping, and poor emotion regulation were entered in the equation, perfectionism traits no longer contributed substantively to the explanation of poor sleep.

Conclusion: Though perfectionism traits seem associated with poor sleep, the direct role of such traits seemed small, when mediating factors such as stress perception and emotion regulation were taken into account.

Keywords: perfectionism, perceived stress, emotion regulation, young adults, sleep quality

\section{Introduction}

There is evidence that sufficient and restoring sleep is associated with a wide variety of increased cognitive performance ${ }^{1,2}$ and emotional processing,, 3 and also with personality traits ${ }^{5}$ such as optimism ${ }^{6}$ and mental toughness. ${ }^{78}$ In contrast, dysfunctional cognitive-emotional processes such as symptoms of depression, ${ }^{9,10}$ anxiety, ${ }^{9}$ and perceived stress ${ }^{11-13}$ are associated with poor sleep quality. As regards the personality traits of perfectionism, numerous studies indicate that perfectionism and poor sleep are associated both cross-sectionally ${ }^{14,15}$ and longitudinally. ${ }^{16,17}$ Perfectionism is understood as a set of cognitive-emotional attitudes such as unrealistically high and rigid standards for performance, fear of failure, excessive self-criticism, and an inability to derive satisfaction from achieved goals. ${ }^{18-20}$ In a search for the developmental origins of perfectionism, Hibbart and Walton ${ }^{21}$ conducted semistructured interviews and observed that unlike nonperfectionist undergraduate students, perfectionists reported feeling pressure from their families to succeed. Moreover, perfectionists also reported that their parents were overly critical of their mistakes when they were growing up. Hibbart and Walton ${ }^{21}$ concluded that perfectionism was a personality trait that seemed to develop over childhood and adolescence as a result of parents' (dysfunctional) expectancies and pressure. 
As regards the definition of the personality trait of perfectionisms, there is agreement that perfectionism consists of a set of dysfunctional cognitive-emotional processes. ${ }^{18-21}$ This definition is important because numerous studies indicate that dysfunctional cognitive-emotional processes cause sleep disturbances. To illustrate, Riemann et a ${ }^{13}$ proposed a cognitive-behavioral and neurobiological model of insomnia to explain this link: briefly, psychological stress and inadequate problem-solving, along with worrying and rumination, lead to sleep disruptions (ie, delayed sleep onset latency, more awakenings after sleep onset, early awakening in the morning). In parallel to these cognitive-emotional processes and sleep disruptions, physiological processes such as an increased secretion of cortisol and orexin, and a decreased secretion of serotonin, lead in the longer term to acute cortical arousal and a deterioration in homeostasis. Riemann et $\mathrm{al}^{13}$ thus explain sleep disturbances as the result of cognitive-emotional processes in conjunction with underlying neurophysiological processes. In addition, Harvey ${ }^{22}$ claims that individuals who suffer from insomnia tend to be overly worried about their sleep and about the daytime consequences of not getting enough sleep. Put simply, people suffering from insomnia maintain sleep disturbances via further dysfunctional cognitive-emotional processes.

However, only a few studies have focused so far on the relationship between perfectionism and sleep, and this relationship deserves particular attention. First, de Azevedo et $\mathrm{al}^{14}$ observed, among a sample of 1,163 undergraduate students aged between 17 and 25 years, that socially prescribed perfectionism was associated with sleep disturbance. Second, Azevedo et $a l^{16}$ showed that socially prescribed perfectionism predicted poor sleep 1 and 2 years later, suggesting therefore that perfectionism traits causally predicted sleep disturbances among young adults. Third, Vincent and Walker ${ }^{15}$ compared perfectionism traits in adults with and without insomnia. The authors observed that relative to noninsomniacs, insomniacs were more likely to report doubts about action, frequent parental criticism, and concerns about action. However, focusing on sleep continuity variables, only the perception of increased parental criticism was associated with delayed sleep onset, whereas all other perfectionism traits (concerns about action, doubts about action) were unrelated to sleep continuity variables. Additionally, fourth, Spiegelhalder et $\mathrm{al}^{23}$ investigated punctuality behavior (here understood as a sign of perfectionist behavior) among patients admitted to the sleep lab and observed that arriving at the sleep lab earlier than arranged was not associated with scores for insomnia, but a strong relationship was observed between polysomnographic sleep parameters and punctuality; short sleep duration was significantly associated with early arrival times at the sleep laboratory, suggesting therefore, that dimensions of perfectionist traits (here, punctuality) may causally be linked to poor sleep. Whereas the pattern of results of the abovementioned studies suggest a bidirectional relationship between poor sleep and perfectionist traits, to our knowledge possible confounders and latent factors have not thus far been taken into account. This might be surprising given that, among dysfunctional cognitive-emotional processes, perceived stress or poor emotion regulation, for example, might contribute to an unknown degree to the explained variance between perfectionism traits and sleep. Fifth, in these respects, and again to our knowledge, Jansson-Fröjmark and Linton ${ }^{17}$ were the first to investigate the predictive value of perfectionism traits for preexisting and future sleep disturbances, while introducing emotional distress as a control. There were two results of interest. First, concerns over mistakes were significantly related to preexisting and future insomnia. Second, when introducing emotional distress as a confounder, none of the perfectionism subscales contributed significantly to the explanation of preexisting or future insomnia. Importantly, we note that the approach of Jansson-Fröjmark and Linton ${ }^{17}$ corresponds to a mediational model of coping, emotional regulation as well as perceived stress in the relationship of trait perfectionism on current sleep disturbance. ${ }^{24-28}$

Collectively, only five scientific studies focused on the relationship between perfectionism and sleep more thoroughly, and only one study ${ }^{17}$ introduced possible mediating or confounding factors. We took these observations into account and investigated the associations between perfectionism traits and sleep pattern, while concomitantly assessing perceived stress, coping strategies, and dimensions of emotion regulation. We believe that the results may be potentially of practical importance in that, by definition, cognitive-behavioral therapies focus on modifying dysfunctional cognitive-emotional processes such as perceived stress, coping, and emotion regulation, while, on the flip side, modifying personality traits, which are products of long-term developmental processes, requires more psychotherapeutic effort, and with uncertain results; accordingly, treating personality-related sleep disturbances would turn out much more difficult. Or simply put, if it turns out that perceived stress, coping, and dysfunctional emotion regulation are responsible for the association between personality traits of perfectionism and sleep, then a cognitive-behavioral 
approach to treat these dysfunctional coping strategies and emotion regulation underlying perfectionism traits and sleep disturbances might be more successful.

The following two hypotheses were formulated: first, following Azevedo et al, ${ }^{16}$ de Azevedo et $\mathrm{al}^{14}$ and Vincent and Walker ${ }^{15}$ we expected a direct association between perfectionism traits and poor sleep. Second, following JanssonFröjmark and Linton ${ }^{17}$ we expected that the significant association between perfectionism and sleep would disappear when introducing perceived stress, coping, and emotion regulation as mediating factors, that is, following others ${ }^{24-28}$ we expected that the association between perfectionism and sleep disturbances would be mediated via coping, emotional regulation, and perceived stress.

\section{Methods}

\section{Sample}

A total of 346 young adults $(\mathrm{M}=23.87$ years; SD [standard deviation $]=1.93 ; 54.6 \%$ females ) took part in the study. They were recruited from among students of the faculties of medicine and psychology at the University of Basel (Switzerland). All participants were informed of the purpose of the study and the voluntary basis of their participation. All participants were assured of the confidentiality of their responses and gave informed consent. Afterwards, they completed a booklet consisting of questionnaires related to perfectionism, sleep, stress, emotion regulation, and mental toughness, as described in more detail in the tools section. After completion, participants received a voucher of CHF15.00 (about $€ 12 / \mathrm{USD} 15.00$ ) for a lunch at the university canteen. The study was approved by the local ethical committee of Basel, Switzerland (Ethic Commission beider Basel, Basel, Switzerland) and performed in accordance with the ethical standards laid down in the Declaration of Helsinki.

\section{Tools}

\section{Perfectionism}

Perfectionism was assessed with the German version (FMPS-D) ${ }^{19}$ of the Frost Multidimensional Perfectionism Scale (FMPS). ${ }^{18}$ This self-report measure consists of 35 items which, following Frost et $\mathrm{al}^{18}$ are divided between the following dimensions: Concern over mistakes, Doubts about actions; Parental expectations; Parental criticism, and Personal standards. Here, however, for the German version, we followed Stöber ${ }^{19}$ and scored the questionnaire for the following dimensions:

1) A composite combining items for concerns over mistakes ("I should be upset if I make a mistake.") and doubts about action ("It takes me a long time to do something 'right'"), labeled Concerns and doubts.

2) A composite combining items for parental expectations (eg, "My parents have expected excellence from me.") and parental criticism (eg, "I never felt like I could meet my parents' expectations.'), labeled Parental expectations and criticisms.

3) Personal standards (eg, "I set higher goals than most people.").

To compute an overall Perfectionism score, scores for the three dimensions were combined. Answers were given on 5-point Likert scales ranging from 0 (= not at all true) to 4 (= definitively true), with higher scores reflecting greater perfectionism (Cronbach's $\alpha=0.90)$.

\section{Subjective sleep}

Participants completed the Insomnia Severity Index (ISI), ${ }^{29}$ a screening tool for insomnia. The seven items, answered on five-point rating scales ( $1=$ not at all, 5= very much), refer to difficulty in falling asleep, difficulties maintaining sleep, increased daytime fatigue, and worrying about sleep. The higher the overall score, the more the respondent is assumed to suffer from insomnia (Cronbach's $\alpha=0.89$ ).

\section{Sleep schedules and sleep-related psychological functioning}

To assess sleep schedules and sleep-related psychological functioning, we administered a brief questionnaire based on the Pittsburgh Sleep Quality Index (PSQI). ${ }^{30}$ This asks about sleep duration (hours), sleep onset latency (minutes), and number of awakenings after sleep onset for the last five working days. Additionally, participants reported, on eight-point Likert-scales, for the mornings: sleep quality ( $8=$ very good sleep quality), feeling of being restored $(8=$ completely restored), mood in the morning ( $8=$ very good mood); during the day: tiredness during the day ( $8=$ very tired; higher scores reflect greater tiredness), and concentration during the day ( $8=$ very good concentration); for the evenings: mood in the evening ( $8=$ very good mood); (Cronbach's $\alpha=0.84$ ).

\section{Perceived stress}

The Perceived Stress Scale ${ }^{31}$ consists of ten items and was used to determine perceived overall stress that occurred over the previous month. Answers were given on five-point rating scales ranging from 1 (never) to 5 (very often), with higher scores reflecting greater perceived stress (Cronbach's $\alpha=0.89$ ). 


\section{Coping with stress}

The questionnaire consists of 18 items and assesses positive and negative coping strategies. ${ }^{32}$ Positive coping strategies are those that reduce tension in both the short- and long-term, including minimizing the situation, controlling the situation, and self-instruction. Negative coping strategies are those that reduce tension in the short-term but increase stress in the long-term, including social withdrawal, rumination, and resignation. Answers were given on five-point rating scales ranging from 1 (very unlikely) to 5 (very likely). The higher the score, the more pronounced is the coping strategy (Cronbach's $\alpha=0.87$ ). Two composite mean scores were computed reflecting positive and negative coping strategies, respectively. To further calculate an overall score for coping strategies, the ratio between positive and negative coping was calculated, with higher ratios reflecting a greater reliance on positive as opposed to negative coping strategies.

\section{Emotion regulation}

To assess emotion regulation, we used The EmotionaleKompetenz-Fragebogen (emotional competencies inventory). ${ }^{33}$ The inventory consists of 62 items and assesses the following dimensions: perception and acknowledgement of own emotions (PAE: "Sometimes I feel sad without knowing why"); regulation and control of own emotions (RCE: "When I feel myself getting angry, I know how to cool down again"); emotional expressivity (EE: "I can express my feelings very well"); perception of others' emotions (POE: "I can perceive and describe my friend's emotions very well"). Answers are given on five-point-Likert scales with the anchor points 1 (= never/not at all true) to 5 (= practically always/ definitively true). Some items are reverse coded. Higher total scores reflect a greater degree of the dimensions described above. Moreover the overall score reflects general emotion regulation (Cronbach's $\alpha=0.89$ ).

\section{Mental toughness}

Participants were asked to fill in the 18-item Mental Toughness Questionnaire, the short form of the MTQ48. ${ }^{34}$ The short form provides a general score for mental toughness. Answers on the MTQ18 are given on five-point Likert-type scales ranging from 1 (= strongly disagree) to 5 (= strongly agree). Items were summed, with higher scores reflecting greater MT (Cronbach's $\alpha=0.91$ ).

\section{Statistical analysis}

First, mean and total scores of all dimensions were $z$-transformed. Next, to calculate the relation between perfectionism traits and sleep parameters (sleep disturbance, sleep duration, sleep onset latency, awakenings after sleep onset, daytime sleepiness), perceived stress, coping, mental toughness, and emotion regulation, a series of Pearson's correlations was calculated.

Finally, to calculate both the direct and indirect relations of perfectionism with sleep disturbance via perceived stress, coping, mental toughness, and emotion regulation, a structural equation model (SEM) was computed, using AMOS $^{\circledR}$ (IBM Corporation, Armonk, NY, USA).

The level of significance was set at $\alpha=0.05$. Except for the SEM, all statistical analyses were calculated with SPSS ${ }^{\circledR}$ 20.0 (IMB Corporation, Armonk, NY, USA) for Apple McIntosh $^{\circledR}$.

\section{Results}

Table 1 provides all descriptive and correlational computations of the variables. Perfectionism traits were associated with sleep disturbances (ISI), more awakenings after sleep onset, lower mood in the morning and in the evening, feeling less restored in the morning, poorer concentration during the day, and greater tiredness during the day. No significant correlations were found for sleep quality, sleep duration, and for sleep onset latency (with one exception).

Perfectionism traits were significantly associated with greater perceived stress, more reliance on negative coping strategies, and less reliance on positive coping strategies. Perfectionisms traits were significantly associated with lower scores for Perception and acknowledgement of own emotion, and the Regulation and control of own emotions. No significant associations were found for Emotional expressivity (with one exception) or for the Perception of others' emotions. Two perfectionism traits (concerns and doubts; personal standards) were associated with lower mental toughness.

\section{Direct and indirect associations between perfectionism and sleep}

To calculate both the direct and indirect effects of perfectionism on sleep disturbance via perceived stress, coping, mental toughness, and emotion regulation, a SEM was computed.

With respect to the goodness of fit criteria as proposed by $\mathrm{Hu}$ and Bentler ${ }^{35}$ and McDonald and Ho, ${ }^{36}$ the model represented a satisfying fit (goodness of fit in square brackets): $\chi^{2} / d f=22.36, P<0.05[<d f$; here, 4], AGFI (adjusted goodness of fit index $)=0.91[\geq 0.95]$, PClose $=0.78$ [ $>0.50]$, CFI (confirmatory fit index) $=0.1791[>0.90]$, RMR (root mean squared residual) $=0.018[<0.08]$ and RMSEA (root mean square error of approximation) $=0.025[\leq 0.05]$. 


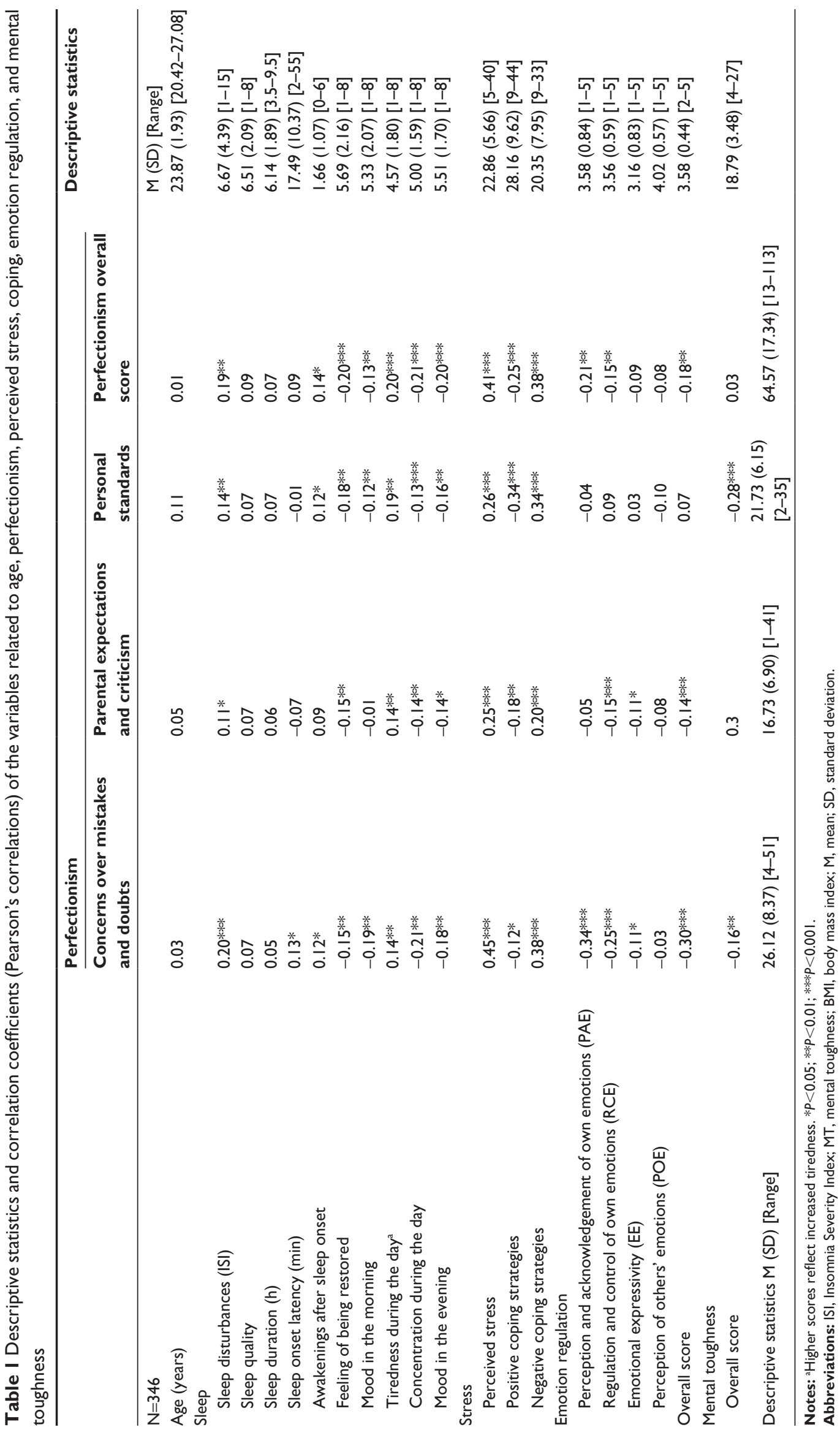


The statistically significant and direct association between perfectionism and sleep disturbances (ISI) was $\beta=0.187$ $(P<001)$.

When perceived stress, coping, emotion regulation, and mental toughness were entered in the equation, the direct effect of perfectionism on sleep disturbance (ISI) decreased to 0 ; sleep disturbance was predicted by greater perceived stress, poor coping, low emotion regulation, and low mental toughness (Figure 1). (Sobel $Z=2.01, P<0.05 ; 95 \%$ asymmetric CI [confidence interval] $=0.01-0.05, P<0.05$ ).

\section{Discussion}

The key findings of the present study are that perfectionism traits were associated with poorer sleep, though if perceived stress, coping, emotion regulation, and mental toughness were entered into the equation, the importance of perfectionism traits dramatically decreased. Therefore, the pattern of results suggests that the underlying psychological mechanisms of perfectionism seem to be greater perceived stress, poor coping, low emotion regulation, and low mental toughness, which are in turn associated with poorer sleep.

Two hypotheses were formulated and each of these is now considered in turn. Our first hypothesis was that there would be a significant association between perfectionism traits and poor sleep, and this hypothesis was supported. In this respect, the present pattern of results concurs with previous research, ${ }^{14-16,23}$ showing that perfectionism, understood as a dysfunctional set of attitudes toward achieving high performance as a function of one's own standards, concerns about mistakes and doubts, but above all as a function of parents' expectations and criticism, is associated with poor sleep. The present study expands upon previous work in that we showed that in a sample of young adults perfectionism traits were also negatively associated with a broad range of psychological processes such as greater perceived stress, poor coping, poor emotion regulation, and low mental toughness, along with increased tiredness and decreased concentration during the day, and lower mood in the morning and in the evening.

Our second hypothesis, however, was that psychological factors such as stress and emotion regulation would mediate the relation between sleep and perfectionism. This hypothesis was derived from the findings of Morin et al ${ }^{24}$ LeBlanc et al ${ }^{25,26}$ and Fernandez-Mendoza et $\mathrm{al}^{27,28}$ who claimed the importance of coping and perceived stress as an important factor to explain the emergence and maintenance of sleep disturbances, and from the study by Jansson-Fröjmark and Linton. ${ }^{17}$ They reported two main findings: first, concerns over mistakes were significantly related to preexisting and future insomnia. Second, when introducing emotional distress as a control, none of the perfectionism subscales contributed significantly to explaining preexisting and future insomnia. We took this pattern of results into account and confirmed the second hypothesis, that is Jansson-Fröjmark and Linton's ${ }^{17}$ observation: when perceived stress, poor coping, low emotion regulation, and low mental toughness were entered in the equation, perfectionism traits were no longer associated with poor sleep, that is to say, they were mediated by coping and perceived stress. Therefore, we conclude that dysfunctional cognitive-emotional processes such as stress perception and coping, and poor emotion

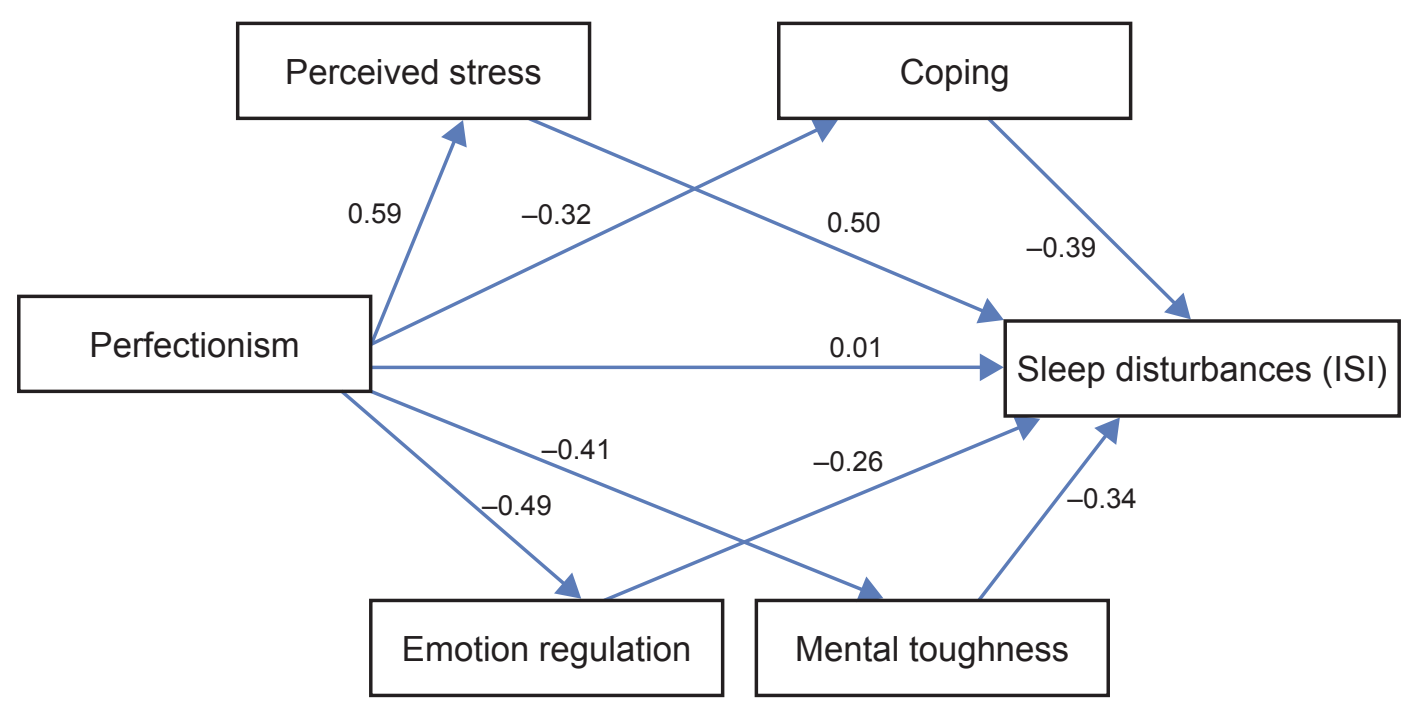

Figure I Structural equation model (SEM) linking perfectionism to perceived stress, coping, emotion regulation, and mental toughness. Note: Indices are regression weights $(\beta)$. 
regulation underlying perfectionist behavior explain most of the association between perfectionism traits as such and poor sleep. Most importantly, the present pattern of results fits well within the large body of research showing that it is not personality traits per se, but the underlying coping strategies and emotion regulation processes, which are predisposing and perpetuating factors of sleep disturbance. ${ }^{24-28}$

The present data do not shed any further light on the reasons for the association between perfectionism and stress or poor emotion regulation, though three overlapping theoretical frameworks support the following possibility. Both Riemann et $\mathrm{al}^{13}$ and Harvey ${ }^{22}$ claim that sleep disturbances are caused and maintained by dysfunctional cognitiveemotional processes; more specifically, Riemann et $\mathrm{al}^{13}$ propose that psychological stress and inadequate problemsolving, along with worrying and rumination, lead to sleep disruptions (ie, delayed sleep onset latency, more awakenings after sleep onset, early awakening in the morning). Importantly, Spiegelhalder et $\mathrm{al}^{23}$ showed that hyper-punctuality among patients admitted to the sleep lab - arriving earlier than agreed at the lab (interpreted here as a form of perfectionist behavior) - was significantly associated with poor polysomnographic sleep parameters. Short sleep duration was significantly associated with early arrival times at the sleep laboratory, suggesting therefore, that aspects of perfectionism (here, punctuality) may be causally linked to poor sleep.

Likewise, Harvey ${ }^{22}$ claims that individuals who suffer from insomnia tend to be overly worried about their sleep and about the daytime consequences of not getting enough sleep or, put simply, people suffering from insomnia maintain sleep disturbances via further dysfunctional cognitive-emotional processes.

Last, Morin et $\mathrm{al}^{24}$ LeBlanc et $\mathrm{al}^{25,26}$ and FernandezMendoza et $\mathrm{al}^{27,28}$ showed that it is not personality traits per se, but the underlying coping strategies and emotion regulation processes, which are predisposing and perpetuating factors of sleep disturbance.

Taken together, the three theoretical frameworks help to explain why it is not perfectionism per se, but rather the underlying psychological mechanisms that best explain the association between perfectionism and poor sleep.

As regards the association between mental toughness (a construct consisting of a high degree of control, commitment, challenge, and confidence; Clough et $\mathrm{al}^{34}$ ) and sleep, we observed that the present pattern of results fits well within previous literature showing that mental toughness was associated with increased subjective $e^{7,37}$ and objective sleep ${ }^{8}$ among adolescents. In this respect, the present findings expand upon earlier results in that the positive association between higher mental toughness and favorable sleep also holds among young adults.

Despite the intriguing results, several limitations warrant against overgeneralization of the results, and findings should be interpreted cautiously. First, participants were recruited from among university students and therefore the sample is not representative of young adults as a whole. More specifically, it remains unanswered to what extent the present sample is representative for other samples of adults such as nonacademic people, older adults, or people suffering from severe insomnia. However, we claim that the present pattern of results is a useful step in differentiating cognitive processes that may impact sleep, which could act as a catalyst for future research in clinical samples. Second, the data consists entirely of self-reports; experts' ratings such as a brief psychiatric interview could have provided further insight into possible psychiatric or personality disorders. Third, and most importantly, sleep was not objectively assessed, leaving it uncertain to what extent participants with poor sleep were also inclined to report poor psychological functioning. Or simply put: there is the risk, that self-reported poor sleep quality was associated with inadequate and negative self-reported psychological functioning. Future studies should therefore also include objective sleep measurements (actigraphy, sleep-EEG [electroencephalogram]), though we also note that for large samples questionnaire-based measures remain the gold standard. ${ }^{38}$ Fourth, no biological markers were assessed, though, specifically, there is evidence that, for instance, cortisol secretion is associated with sleep and stress regulation. Further, BDNF as indicator of neuronal plasticity plays a role in insomnia and coping with stress. ${ }^{39}$ Fifth, the present pattern of results might have emerged due to further latent but unassessed variables. Sixth, no cognitive-academic performance was assessed, which is a global concern for students; accordingly, a wealth of studies shows the association between cognitive abilities, academic performance, and sleep. ${ }^{1,40}$ Last, the cross-sectional design of the study precludes any conclusion as to the direction of influence between perfectionism traits, perceived stress, coping, mental toughness, and sleep, and Haario et $\mathrm{al}^{41}$ showed the bidirectional association between sleep and psychological functioning. Longitudinal studies such as the research of Jansson-Fröjmark and Linton ${ }^{17}$ and Azevedo et a ${ }^{16}$ allow for a more detailed picture as to the cause-effect relationship between perfectionism and sleep. 


\section{Conclusions}

The pattern of results suggests that among a sample of young adults, perfectionism traits are related to poor sleep, though cognitive-emotional processes such as stress, coping, and emotion regulation underlying perfectionism traits better explain variance in sleep than perfectionism traits per se. In our opinion, these results should allow more focused and successful psychotherapeutic treatment of perfectionist patients suffering from poor sleep. However, to further prove these observations, the present pattern of results should be replicated among clinical samples.

\section{Acknowledgments}

We thank Gioia Schultheiss for text editing and Nick Emler (University of Surrey, UK) for proofreading the manuscript.

\section{Funding}

The entire study was conducted without external funding.

\section{Disclosure}

The authors report no conflicts of interest in this work. The authors alone are responsible for the content and writing of the article.

\section{References}

1. Curcio G, Ferrara M, De Gennaro L. Sleep loss, learning capacity and academic performance. Sleep Med Rev. 2006;10:323-337.

2. Van Dongen HP, Maislin G, Mullington JM, Dinges DF. The cumulative cost of additional wakefulness: dose-response effects on neurobehavioral functions and sleep physiology from chronic sleep restriction and total sleep deprivation. Sleep. 2003;26:117-126.

3. Talbot LS, McGlinchey EL, Kaplan KA, Dahl RE, Harvey AG. Sleep deprivation in adolescents and adults: changes in affect. Emotion. 2010;10:831-841.

4. Yoo SS, Gujar N, Hu P, Jolesz FA, Walker MP. The human emotional brain without sleep - a prefrontal amygdala disconnect. Curr Biol. 2007; 17:R877-R878.

5. van de Laar M, Verbeek I, Pevernagie D, Aldenkamp A, Overeem S. The role of personality traits in insomnia. Sleep Med Rev. 2010;14:61-68.

6. Lemola S, Räikkönen K, Scheier MF, et al. Sleep quantity, quality and optimism in children. J Sleep Res. 2011;20:12-20.

7. Brand S, Gerber M, Kalak N, et al. "Sleep well, our tough heroes!"-in adolescence, greater mental toughness is related to better sleep schedules. Behav Sleep Med. 2014;12(6):444-454.

8. Brand S, Gerber M, Kalak N, et al. Adolescents with greater mental toughness show higher sleep efficiency, more deep sleep and fewer awakenings after sleep onset. $J$ Adolesc Health. 2014;54:109-113.

9. Alvaro PK, Roberts RM, Harris JKA. Systematic review assessing bidirectionality between sleep disturbances, anxiety, and depression. Sleep. 2013;36:1059-1068.

10. Lovato N, Gradisar M. A meta-analysis and model of the relationship between sleep and depression in adolescents: recommendations for future research and clinical practice. Sleep Med Rev. Epub April 12, 2014.
11. Gerber M, Brand S, Feldmeth AK, et al. Adolescents with high mental toughness adapt better to perceived stress: a longitudinal study with Swiss vocational students. J Pers Individ Diff. 2013;54:808-814.

12. Harvey CJ, Gehrman P, Espie CA. Who is predisposed to insomnia: a review of familial aggregation, stress-reactivity, personality and coping style. Sleep Med Rev. 2014;18:237-247.

13. Riemann D, Spiegelhalder K, Feige BK, et al. The hyperarousal model of insomnia: a review of the concept and its evidence. Sleep Med Rev. 2010;14:19-31.

14. de Azevedo MH, Soares MJ, Bos SC, et al. Perfectionism and sleep disturbance. World J Biol Psychiatry. 2009;10:225-233.

15. Vincent NK, Walker JR. Perfectionism and chronic insomnia. J Psychosom Res. 2000;49:349-354.

16. Azevedo MH, Bos SC, Soares MJ, et al. Longitudinal study on perfectionism and sleep disturbance. World J Biol Psychiatry. 2010;11:476-485.

17. Jansson-Fröjmark M, Linton SJ. Is perfectionism related to preexisting and future insomnia? A prospective study. Br J Clin Psychol. 2007;46:119-124.

18. Frost RO, Marten P, Lahart C, Rosenblate R. The dimensions of perfectionism. Cognit The Res. 1990;14:449-468.

19. Stöber J. The Frost Multidimensional Perfectionism Scale: More perfect with four (instead of six) dimensions. Pers Individ Diff. 1998;24: 481-491.

20. Stöber J, Joormann J. Worry, procrastination, and perfectionism: differentiating amount of worry, pathological worry, anxiety, and depression. Cognit Ther Res. 2001;25:49-60.

21. Hibbart DR, Walton GE. Where does perfectionism come from? A qualitative investigation of perfectionists and nonperfectionists. Social Behav Pers. 2012;40:1121-1122.

22. Harvey AG. A cognitive model of insomnia. Behav Res Ther. 2002;40:869-893.

23. Spiegelhalder K, Regen W, Kyle SD, et al. Time will tell: a retrospective study investigating the relationship between insomnia and objectively defined punctuality. J Sleep Res. 2012;21:264-269.

24. Morin CM, Rodrigue S, Ivers H. Role of stress, arousal, and coping skills in primary insomnia. Psychosom Med. 2003;65:259-267.

25. LeBlanc M, Beaulieu-Bonneau S, Mérette C, Savard J, Ivers H, Morin CM. Psychological and health-related quality of life factors associated with insomnia in a population-based sample. JPsychosom Res. 2007; 63:157-166.

26. LeBlanc M, Mérette C, Savard J, Ivers H, Baillargeon L, Morin CM. Incidence and risk factors of insomnia in a population-based sample. Sleep. 2009;32:1027-1037.

27. Fernández-Mendoza J, Vela-Bueno A, Vgontzas AN, et al. Cognitiveemotional hyperarousal as a premorbid characteristic of individuals vulnerable to insomnia. Psychosom Med. 2010;72:397-403.

28. Fernandez-Mendoza J, Shaffer ML, Olavarrieta-Bernardino S, et al. Cognitive-emotional hyperarousal in the offspring of parents vulnerable to insomnia: a nuclear family study. J Sleep Res. 2014;23:489-498.

29. Bastien CH, Vallières A, Morin CM. Validation of the Insomnia Severity Index as an outcome measure for insomnia research. Sleep Med. 2001;2:97-307.

30. Buysse DJ, Reynolds CF, Monk TH, Berman SR, Kupfer DJ. The Pittsburgh Sleep Quality Index: new instrument for psychiatric practice and research. Psychiatry Rev. 1989;28:193-213.

31. Cohen S, Kamarck T, Mermelstein R. A global measure of perceived stress. J Health Social Behav. 1983;24:385-396.

32. Janke W, Erdmann G. Stressverabeitungsfragebogen SVF-120. [Stress coping questionnaire]. Hogrefe: Göttingen; 2008.

33. Rindermann H. Emotionale-Kompetenz-Fragebogen. [emotional competence questionnaire]. Hogrefe: Göttingen; 2009.

34. Clough P, Earle K, Sewell D. Mental toughness: the concept and its measurement. In: Cockerill I, editor. Solutions in Sport Psychology. London UK: Thomson Learning; 2002:32-46. 
35. Hu LT, Bentler PM. Cutoff criteria for fit indexes in covariance structure analysis: conventional criteria versus new alternatives. Struct Equ Model. 1999;6:1-55.

36. McDonald RP, Ho MH. Principles and practice in reporting structural equation analyses. Psychol Meth. 2002;7:64-82.

37. Brand S, Kalak N, Gerber M, et al. During early and mid-adolescence, greater mental toughness is related to increased sleep quality and quality of life. J Health Psychol. Epub July 24, 2014.

38. Wolfson AR, Carskadon MA, Acebo C, et al. Evidence for the validity of a sleep habits survey for adolescents. Sleep. 2003;26:213-216.
39. Giese M, Unternährer E, Hüttig $\mathrm{H}$, et al. BDNF: an indicator of insomnia? Mol Psychiatry. 2014;19:151-152.

40. Esposito M, Antinolfi L, Gallai B, et al. Executive dysfunction in children affected by obstructive sleep apnea syndrome: an observational study. Neuropsychiatr Dis Treat. 2013;9:1087-1094.

41. Haario P, Rahkonen O, Laaksonen M, Lahelma E, Lallukka T. Bidirectional associations between insomnia symptoms and unhealthy behaviours. J Sleep Res. 2013;22:89-95.

\section{Publish your work in this journal}

Neuropsychiatric Disease and Treatment is an international, peerreviewed journal of clinical therapeutics and pharmacology focusing on concise rapid reporting of clinical or pre-clinical studies on a range of neuropsychiatric and neurological disorders. This journal is indexed on PubMed Central, the 'PsycINFO' database and CAS, and is the official journal of The International Neuropsychiatric Association (INA). The manuscript management system is completely online and includes a very quick and fair peer-review system, which is all easy to use. Visit http://www.dovepress.com/testimonials.php to read real quotes from published authors.

Submit your manuscript here: http://www.dovepress.com/neuropsychiatric-disease-and-treatment-journal 